\title{
Pengaruh Media Pembelajaran CD Interaktif Melalui Pembelajaran Daring di Era Pandemi Covid-19 Terhadap Hasil Belajar IPA
}

\author{
Sry Rahayu Pobela ${ }^{*}$, Jovialine A. Rungkat ${ }^{2}$ \\ 1,2 Jurusan Pendidikan IPA, FMIPA, Universitas Negeri Manado \\ "e-mail: sryrahayupobela@gmail.com
}

\begin{abstract}
Abstrak. Penelitian ini bertujuan untuk melihat pengaruh media pembelajaran CD interaktif melalui pembelajaran daring di era pandemi Covid-19 terhadap hasil belajar pada mata pelajaran IPA di SMP Negeri 7 Kotamobagu. Penelitian ini merupakan penelitian eksperimen semu menggunakan rancangan pretest posttest randomized two group design. Populasi dalam penelitian ini adalah seluruh kelas VIII di SMP Negeri 7 Kotamobagu dan sampel penelitian terdiri dari 2 kelas, yaitu kelas VIII A sebagai kelas eksperimen yang berjumlah 32 siswa dan kelas VIII B sebagai kelas kontrol yang berjumlah 27 siswa. Pengambilan data dilakukan dengan memberikan pretest sebelum diberikan perlakuan dan posttest sesudah diberikan perlakuan. Hasil penelitian yang diperoleh berupa selisih nilai rata-rata hasil pretest dan posttest pada kelas eksperimen sebesar 48,28 sedangkan untuk kelas kontrol 33,15. Setelah diuji statistik melalui uji-t, rata-rata hasil belajar yang didapat antara kelas kontrol dan kelas eksperimen diperoleh thitung $=10,58>t_{\text {tabel }}=2,004$. Dengan demikian dapat disimpulkan bahwa terdapat pengaruh media pembelajaran CD interaktif melalui pembelajaran daring di era pandemi Covid-19 terhadap hasil belajar pada mata pelajaran IPA di SMP Negeri 7 Kotamobagu
\end{abstract}

Kata kunci: media interaktif, hasil belajar, sistem pencernaan

\begin{abstract}
This study aims to see the effect of interactive CD learning media through online learning in the era pandemic Covid-19 on learning outcomes in science subjects at SMP Negeri 7 Kotamobagu. This research is a quasi-experimental research using pretest posttest randomized two group design. The population in this study were all class VIII at SMP Negeri 7 Kotamobagu and the research sample consisted of 2 classes, namely class VIII $A$ as the experimental class which amounted to 32 students and class VIII B as the control class which amounted to 27 students. Data collection was carried out by giving a pretest before being given treatment and a posttest after being given treatment. The results obtained in the form of the difference in the average value of the pretest and posttest results in the experimental class of 48.28 while for the control class 33.15. After being tested statistically through the t-test, the average learning outcomes obtained between the control class and the experimental class were obtained $t_{\text {count }}=10.58>t_{\text {table }}=$ 2.004. Thus, it can be concluded that there is an influence of interactive CD learning media through online learning in the era of the Covid-19 pandemic on learning outcomes in science subjects at SMP Negeri 7 Kotamobagu
\end{abstract}

Keywords: media interactive, learning outcomes, digestive system Diterima 13 April 2021 | Disetujui 22 Juni 2021 | Diterbitkan 30 Juni 2021

\section{PENDAHULUAN}

Pendidikan merupakan sumber kemajuan bangsa yang sangat menentukan daya saing bangsa, oleh karena itu mutu sektor pendidikan harus terus menerus ditingkatkan. Faktor kesenjangan pendidikan menjadi salah satu faktor utama dalam meningkatkan 
mutu pendidikan. Untuk mengatasi kesenjangan tersebut pemerintah telah berupaya melakukan perubahan melalui beberapa kebijakan dalam bidang pendidikan. Salah satu upaya kebijakan yang dikeluarkan pemerintah ialah pemberlakuan kurikulum 2013 yang tujuannya agar siswa lebih aktif dalam proses pembelajaran di kelas.

Salah satu permasalahan pendidikan yang dihadapi saat ini adalah rendahnya kualitas pendidikan. Rendahnya kualitas pendidikan terjadi karena banyak fakotr. Berbagai usaha telah dilakukan untuk meningkatkan kualitas pendidikan nasional antara lain menyempurnakan kurikulum, pengadaan buku, melengkapi sarana dan prasarana, memperbarui model dan metode pembelajaran serta berbagai pelatihan dan peningkatan kualitas guru (Romadhoni, Mahardika \& Harijanto, 2017).

Guru harus mampu menciptakan situasi pembelajaran yang menyenangkan, mampu mendorong motivasi belajar dan meningkatkan hasil belajar peserta didik dalam artian peserta didik tidak hanya menguasai pengetahuan yang diajarkan, tetapi pengetahuan tersebut telah menjadi muatan nurani peserta didik yang nantinya dapat dihayati dan peserta didik terapkan secara optimal dalam kehidupan sehari-hari. Agar tercipta situasi belajar yang menyenangkan, guru harus memperhatikan beberapa faktor yang mempengaruhi keberhasilan proses belajar mengajar. Menurut Arsyad (2006), dalam proses belajar mengajar, dua unsur yang amat penting adalah metode mengajar dan media pembelajaran. Kedua unsur ini saling berkaitan satu sama lain.

Perkembangan teknologi saat ini sudah semakin pesat, baik teknologi informasi maupun teknologi komunikasi. Teknologi ini akan sangat berguna jika digunakan dalam menunjang perkembangan pembelajaran di dunia pendidikan.

Mata pelajaran IPA pada hakekatnya memiliki dua dimensi yaitu IPA sebagai produk dan IPA sebagai proses (Neka, Marhaeni \& Suastra, 2015). Oleh karena itu, media baik untuk digunakan dalam pelajaran IPA di sekolah.

Berdasrkan hasil observasi di SMP Negeri 7 Kotamobagu, diperoleh beberapa permasalahan diantaranya belum menerapkan media pembelajaran yang efektif dan efisien, sehingga membuat siswa kesulitan untuk memahami materi, siswa masih merasa bosan dengan proses pembelajaran yang ada, metode mengajar masih bersifat konvensional seperti ceramah sehingga siswa lebih pasif dalam kegiatan belajar. Motivasi dan minat belajar siswa juga masih kurang pada saat proses pembelajaran berlangsung. Sehingga perlu dilakukan peninjauan ulang dalam proses belajar agar hasil belajar siswa lebih meningkat. Hasil belajar siswa berdasarkan nilai-nilai ulangan pada mata pelajaran IPA tahun ajaran 2020/2021 mengalami masalah, dimana masalah tersebut terjadi karena siswa tidak mencapai Kriteria Ketuntasan Minimal (KKM) yang ditetapkan oleh sekolah yaitu 70 .

Hasil belajar dapat diartikan apabila seseorang telah belajar akan terjadi perubahan tingkah laku pada orang tersebut, misalnya dari tidak tahu menjadi tahu dan tidak mengerti menjadi mengerti (Hamalik, 2012). Lebih lanjut, hasil belajar juga merupakan hasil dari suatu interaksi tindak belajar dan tindak mengajar (Dimyati \& Mudjiono, 2015).

Guru memiliki peranan yang sangat penting untuk memperhatikan masalah tersebut dalam meningkatkan hasil belajar siswa. Solusi yang dapat di lakukan oleh guru adalah menggunakan media pembelajaran. Adapun media yang dapat guru gunakan untuk meningkatkan hasil belajar IPA ialah dengan penggunaan Compact Disk (CD) Interaktif. CD dapat mengakses berbagai macam data dan obyek yang tidak dapat dilihat secara langsung, karena faktor lokasi yang jauh atau proses yang memakan waktu sangat lama.

Media sebagai segala bentuk dan saluran yang digunakan orang untuk menyalurkan pesan/informasi. CD dapat dilengkapi dengan narasi atau suara lain 
yang dapat ditangkap dengan indera pendengaran. CD pembelajaran semacam ini disebut dengan CD pembelajaran interaktif atau audiovisual interaktif yang dikendalikan dengan komputer dan dapat ditampilkan dengan LCD. CD interaktif juga dapat membantu mempertajam pesan yang disampaikan dengan kelebihannya menarik indera dan menarik minat, karena merupakan gabungan antara pandangan, suara, dan gerakan (Nursalim \& Naqiyah, 2010).

Media pembelajaran adalah suatu alat, metode atau teknik untuk menyampaikan informasi kepada penerima pesan yang digunakan untuk memudahkan proses penyampaian informasi oleh guru dengan siswa dalam proses pembelajaran di sekolah (AlTabany, 2015). Selain menggunakan CD interaktif penggunaan LKS juga dapat meningkatkan hasil belajar siswa (Suardani, Lasmawan \& Sadia, 2013).

Pemerintah pusat hingga pemerintah daerah dalam hal ini Menteri Pendidikan dan Kebudayaan Indonesia mengeluarkan kebijakan untuk belajar dari rumah. Hal tersebut dilakukan sebagai upaya pencegahan meluasnya penularan Covid-19. Hingga saat ini di Indonesia beberapa sekolah hingga kampus baik swasta maupun negeri mulai menerapkan kebijakan kegiatan belajar mengajar jarak jauh atau pembelajaran berbasis online dengan memanfaatkan aplikasi pembelajaran online yang ada seperti google classroom, zoom meeting dan sebagainya.

Oleh karena itu, pembelajaran daring dalam penelitian ini dilakukan dengan memutar media CD interaktif kemudian mengajar pada siswa secara daring atau online. Pembelajaran dengan menggunakan media CD interaktif melalui pembelajaran daring selama masa pandemi diharapkan dapat meningkatkan hasil belajar siswa karena didalamnya terdapat materi yang merupakan penggabungan antara media gambar, suara dan gerakan.

E-Learning adalah suatu proses pembelajaran jarak jauh dengan cara menggabungkan prinsip-prinsip di dalam proses suatu pembelajaran dengan teknologi (Allen, 2013). Oleh karena itu, peneliti melakukan penelitian terhadap hasil belajar dalam pembelajaran IPA dengan menggunakan media pembelajaran CD Interaktif pada ranah kognitif dalam aspek menerapkan (application) (C3) dan menganalisis (analysis) (C4).

Salah satu pendekatan pembelajaran yang diharapkan dapat menumbuhkan rasa senang (joyful learning) adalah dengan menggunakan pendekatan CD Interaktif (Widiyatmoko, 2012). Oleh karena itu, tujuan dari penelitian ini adalah untuk mengetahui pengaruh penggunaan media CD interaktif pada pembelajaran IPA materi sistem pencernaan di kelas VII SMP Negeri 7 Kotamobagu.

\section{METODE PENELITIAN}

Penelitian ini dilaksanakan di kelas VIII SMP Negeri 7 Kotamobagu dan waktu penelitian ini dilaksanakan pada bulan oktober semester ganjil tahun ajaran 2020/2021. Metode penelitian yang digunakan adalah metode quasi eksperimental design berupa nonequivalent control group design. Rancangan yang digunakan dalam penelitian ini adalah pretest posttest randomized two group design. Desain penelitian dapat dilihat pada Tabel 1.

Tabel 1. Desain model penelitian

\begin{tabular}{cccc}
\hline Kelompok & Pretest & $\begin{array}{c}\text { Variabel } \\
\text { Bebas }\end{array}$ & Posttest \\
\hline r E & $\mathrm{Y}_{1}$ & $\mathrm{X}_{1}$ & $\mathrm{Y}_{2}$ \\
r P & $\mathrm{Y}_{1}$ & $\mathrm{X}_{2}$ & $\mathrm{Y}_{2}$ \\
\hline & & \multicolumn{2}{c}{ (Sugiyono, 2016) }
\end{tabular}

Desain penelitian pada Tabel 1 menunjukkan kelompok eksperimen ( $\mathrm{r}$ E) yang diberikan perlakuan menggunakan media CD interaktif $\left(\mathrm{X}_{1}\right)$ sedangkan pada kelompok kontrol ( $\mathrm{r} \quad \mathrm{P})$ diberikan perlakuan pembelajaran konvensional $\left(\mathrm{X}_{2}\right)$. Setiap kelas diberikan pretest $\left(\mathrm{Y}_{1}\right)$ dan posttest $\left(\mathrm{Y}_{2}\right)$. dan posttest untuk kelas kontrol $\left(\mathrm{O}_{4}\right)$.

Dalam rancangan ini digunakan dua kelompok sampel yaitu kelas VIII A sebanyak 32 siswa sebagai kelas eksperimen dan kelas VIII B sebanyak 27 
siswa sebagai kelas kontrol. Dengan prosedur pelaksanaan sebagai berikut: (1) Pilih sejumlah sampel dari suatu populasi secara rambang. (2) Kelompokkan sampel tersebut menjadi dua kelompok, yaitu kelompok eksperimen dan kelompok kontrol secara rambang. (3) Pertahankan agar kondisi bagi kedua kelompok itu tetap sama, kecuali satu hal yaitu kelompok eksperimen dikenai variabel eksperimen X. (4) Kenakan tes T2 yaitu variabel tergantung kepada kedua kelompok itu. (5) Hitung mean masing-masing kelompok, yaitu kelompok eksperimen dan kelompok kontrol dan cari perbedaan antara dua mean itu. (6) Terapkan test statistik untuk menguji apakah terdapat perbedaan yang signifikan, yaitu cukup besar untuk menolak hipotesis nol.

Instrumen yang digunakan sebagai alat untuk memperoleh data yang diperlukan oleh peneliti dalam kegiatan penelitian yaitu observasi dan tes. Tes yang digunakan yaitu tes essay, sebelum instrumen hasil belajar tersebut digunakan terlebih dahulu sudah dilakukan uji validitas.

Data hasil belajar siswa dikumpulkan dengan memberikan tes sebelum dan tes sesudah pembelajaran selesai pada materi IPA, sebelum tes tersebut diberikan terlebih dahulu akan diuji validitas dan reliabilitas. Selanjutnya, data diuji dengan prasyarat analisis yang terdiri dari uji normalitas dan homogenitas. Tahap terakhir adalah uji hipotesis.

Hipotesis dalam penelitian ini yaitu: $\mathrm{H}_{0}: \mu_{1} \leq \mu_{2}$ : rata-rata hasil belajar IPA pada materi sistem pencernaan dengan menggunakan media pembelajaran interaktif $\left(\mu_{1}\right)$ lebih rendah atau sama dengan rata-rata hasil belajar IPA siswa dengan menggunakan model pembelajaran konvensional $\left(\mu_{2}\right)$

$\mathrm{H}_{\mathrm{a}}: \mu_{1}>\mu_{2}$ : rata-rata hasil belajar IPA pada materi sistem pencernaan dengan menggunakan media pembelajaran interaktif $\left(\mu_{1}\right)$ lebih tinggi dari hasil belajar IPA siswa dengan menggunakan model pembelajaran konvensional atau ceramah $\left(\mu_{2}\right)$.

\section{HASIL DAN PEMBAHASAN}

Penelitian ini menggunakan dua kelas yang telah diambil secara acak yaitu kelas VIII A yang berjumlah 32 siswa sebagai kelas eksperimen dan VIII B dengan jumlah 27 siswa sebagai kelas kontrol. Kelas eksperimen merupakan kelas yang diberikan perlakuan menggunakan media CD interaktif dan untuk kelas kontrol diberikan perlakuan pembelajaran konvensional (ceramah) dengan materi sistem pencernaan pada manusia. Pembelajaran yang dilakukan juga merupakan pembelajaran daring dimana media yang digunakan yaitu WhatsApp dan Zoom Meeting dengan setiap pertemuan yang dilakukan didasari dari RPP yang telah disediakan terlebih dahulu. Untuk kelas eksperimen selain menggunakan RPP juga menggunakan LKS sistem pencernaan pada manusia yang didalamnya terdapat pertanyaanpertanyaan yang sudah disediakan terlebih dahulu oleh peneliti. Materi pembelajaran menggunakan media CD interaktif diambil dari video pada kanal youtube Norhidayati yang dipublikasikan pada 11/10/2020 dengan durasi video 13:45 menit.

Berdasarkan hasil penelitian yang dilakukan pada kelas eksperimen dan kelas kontrol, diperoleh hasil pretest dan posttest pada kedua kelas. Hasil yang diperoleh menunjukan bahwa nilai ratarata hasil posttest kelas eksperimen yang dicapai peserta didik adalah 78,93 lebih tinggi dari nilai rata-rata posttest kelas kontrol yaitu 66,38. Untuk rekapitulasi hasil belajar siswa kelas eksperimen dan kelas kontrol dapat dilihat pada Tabel 2 dan Tabel 3.

Tabel 2. Rekapitulasi skor hasil belajar kelas eksperimen

\begin{tabular}{llll}
\hline Statistik & Pretest & Posttest & Selisih \\
\hline Rata-rata & 30,62 & 78,90 & 48,28 \\
$\begin{array}{l}\text { Skor } \\
\text { maksimum }\end{array}$ & 15 & 70 & 55 \\
$\begin{array}{l}\text { Skor } \\
\text { minimum }\end{array}$ & 60 & 85 & 25 \\
$\begin{array}{l}\text { Standar } \\
\text { deviasi }\end{array}$ & 14,79 & 5,03 & 9,75 \\
Varians & 218,95 & 25,37 & 193,57 \\
\hline
\end{tabular}


Tabel 3. Rekapitulasi skor hasil belajar kelas kontrol

\begin{tabular}{llll}
\hline Statistik & Pretest & Posttest & Selisih \\
\hline $\begin{array}{l}\text { Rata-rata } \\
\text { Skor }\end{array}$ & 31,48 & 64,62 & 33,15 \\
maksimum & 15 & 50 & 35 \\
$\begin{array}{l}\text { Skor } \\
\text { minimum }\end{array}$ & 55 & 75 & 20 \\
$\begin{array}{l}\text { Standar } \\
\text { deviasi }\end{array}$ & 14,12 & 6,03 & 8,09 \\
Varians & 199,64 & 36,39 & 163,24 \\
\hline
\end{tabular}

Berdasarkan Tabel 2 dan Tabel 3 dapat dilihat bahwa hasil pretest dan posttest pada kelas eksperimen dengan nilai rata-rata pretest 30,62 dan posttest 78,90 sedangkan nilai rata-rata pada kelompok kontrol untuk pretest 31,48 dan posttest 64,62. Maka hipotesis dari hasil pengujian dengan melakukan uji-t diperoleh thitung $=10,58$ dan tabel $=2,002$ dengan kriteria pengujian jika thitung $>t_{\text {tabel }}$ maka $\mathrm{H}_{0}$ ditolak dan $\mathrm{H}_{\mathrm{a}}$ diterima.

Perbedaan hasil belajar menunjukan bahwa strategi pembelajaran media CD interaktif dapat meningkatkan hasil belajar siswa. Hal ini dapat dilihat dari hasil belajar media pembelajaran CD interaktif lebih tinggi dari rata-rata hasil belajar siswa dengan menggunakan pembelajaran konvensional. Hal ini dikarenakan media CD interaktif melalui pembelajaran daring di era pandemi saat ini sangat efektif untuk digunakan, mengingat saat ini adalah masa pandemi Covid-19 dimana kebanyakan aktivitas siswa dilakukan di rumah. Dengan adanya media pembelajaran ini lebih memudahkan guru menyampaikan materi kapada siswa, materi yang disampaikan berupa video, buku digital ataupun materi lainnya yang tentunya bisa disimpan ke dalam CD dan bertahan untuk waktu yang lama. Guru dapat memutar atau mengirim video secara langsung kepada siswa. Selain itu, media CD interkatif sangat tepat digunakan pada masa pandemi seperti sekarang ini. Semua materi pembelajaran berupa video, salinan materi serta soal pembelajaran dapat disimpan dalam CD kemudian nanti bisa diajarkan melalui WhatsApp.

Konsep dan masalah dalam materi pembelajaran yang sebelumnya hanya dituliskan dan digambarkan dengan buku maka selanjutnya dapat ditampilkan dalam betuk tayangan media CD interaktif melalui bantuan komputer (Asikin, 2008).

Hasil penelitian ini didukung oleh beberapa hasil penelitian sebelumnya yang relevan, diantaranya penelitian yang dilakukan oleh Musyarofah (2011), yang hasil penelitiannya menunjukkan penggunaan CD interaktif dapat meningkatkan hasil belajar siswa. Selanjutnya penelitian dari Andriyani (2014), Angreni (2017) serta Irsyad, Andrizal \& Putra (2018) yang hasil penelitiannya sama-sama menunjukkan bahwa media Compact Disk (CD) interaktif dapat mempengaruhi dan meningkatkan hasil belajar sehingga media CD interaktif efektif dan efisien untuk digunakan.

\section{KESIMPULAN}

Berdasarkan hasil penelitian dapat disimpulkan bahwa terdapat pengaruh media pembelajaran CD interaktif melalui pembelajaran daring di era pandemi Covid-19 terhadap hasil belajar pada mata pelajaran IPA di SMP Negeri 7 Kotamobagu.

\section{DAFTAR PUSTAKA}

Al-Tabany, T. I. B. (2015). Mendesain Model Pembelajaran Inovatif, Progresif, dan Konstekstual. Jakarta: Prenada Media Group.

Allen, M. (2013). Michael Allen's Guide to E-learning. Canada: John Wiley \& Sons.

Andriyani, Y. (2014). Pengaruh Penggunaan CD Interaktif Dalam Model Pembelajaran Langsung Terhadap Hasil Belajar IPA (Kuasi Eksperimen di SMP Negeri 5 Tangerang). Skripsi. UIN Syarif Hidayatullah Jakarta.

Angreni, S. (2017). Pengaruh Penggunaan Media Interaktif Disertai LKS Terhadap Hasil Belajar IPA Pada Kelas IX SMP. Scientiae Educatia: Jurnal Pendidikan Sains, 6(1), 36-40.

Arsyad, A. (2006). Media Pembelajaran. Jakarta: Rineka Cipta 
Asikin, M. (2008). Pengaruh Model Pembelajaran Matematika Creative Problem Solving (CPS) Berbantuan CD Interaktif Terhadap Kemampuan Pemecahan Masalah Pada Siswa SMA Kelas X. Lembaran Ilmu Kependidikan, 37(1).

Dimyati \& Mudjiono. (2015). Belajar dan Pembelajaran. Jakarta: Rineka Cipta.

Hamalik, O. (2012). Psikologi Belajar dan Mengajar. Bandung: Sinar Baru Algesindo.

Irsyad, I., Andrizal, A., \& Putra, D. S. (2018). Pengaruh Penggunaan Media Pembelajaran CD Interaktif Terhadap Hasil Belajar Siswa Pada Mata Diklat Pemeliharaan Kelistrikan Kendaraan Ringan Kelas XI Program Studi Teknik Otomotif SMK Negeri 1 Padang. Automotive Engineering Education Journals, 1(1), 37-41.

Suardani, K. E., Lasmawan, I. W., \& Sadia, I. W. (2013). Pengaruh Media CD Interaktif Berbantuan LKS Terhadap Motivasi dan Hasil Belajar IPA Kelas V di SD 1, 2, 5 BanyuasriSingaraja. Jurnal Pendidikan Dasar Ganesha, 3(1).

Musyarofah, S. (2011). Upaya Peningkatan Hasil Belajar Peserta Didik Kelas VIII M.Ts. N Jeketro Grobogan. Materi Pokok Sistem Pencernaan Pada Manusia Melalui Penggunaan CD Interaktif Sebagai Media Pembelajaran Biologi Tahun 2010/2011. Skripsi. IAIN Walisongo Semarang.

Neka, I. K., Marhaeni, A. A. I. N., \& Suastra, I. W. (2015). Pengaruh Model Pembelajaran Inkuiri Terbimbing Berbasis Lingkungan Terhadap Keterampilan Berpikir Kreatif dan Penguasaan Konsep IPA Kelas V SD Gugus VIII Kecamatan Abang. Jurnal Pendidikan Dasar Ganesha, 5(1), 1-11.

Nursalim, M., \& Naqiyah, N. (2010). Media Bimbingan dan Konseling. Surabaya: Unesa University Press.

Romadhoni, I., Mahardika, I. K., \& Harijanto, A. (2017). Penerapan Model Pembelajaran Problem Based Learning (PBL) Disertai Media CD Interaktif Terhadap Hasil Belajar dan Aktivitas Belajar Siswa Pada Pembelajaran
Fisika SMA di Kabupaten Bondowoso. Jurnal Pembelajaran Fisika, 5(4), 329336.

Sugiyono. (2016). Metode Penelitian Kuantitatif, Kualitatif dan $R \& D$. Bandung: Alfabeta.

Widiyatmoko, A. (2012). Pengembangan Perangkat Pembelajaran IPA Fisika Dengan Pendekatan PhysicsEdutainment Berbantuan CD Pembelajaran Interaktif. Journal of Primary Education, 1(1). 